\title{
Da Escola de Chicago ao Nacional-desenvolvimentismo: Saúde e Naçăo no pensamento de Alberto Guerreiro Ramos (1940 - 1950)
}

MARGOS GHOR MAIO

THIAGO DA GOSTA LOPES

\section{Resumo}

O artigo explora a interface entre Saúde Pública e Ciências Sociais no pensamento de Alberto Guerreiro Ramos (1940-1950), à luz de sua trajetória intelectual e do desenvolvimento daquelas disciplinas no Brasil. Indica-se como a Saúde foi um elemento-chave para as interpretações de Guerreiro Ramos sobre a Nação e sobre o papel que as Ciências Sociais deveriam assumir no processo de modernização da sociedade. Iniciando sua carreira em agências governamentais, seus primeiros trabalhos sobre Saúde e Infância foram inspirados por abordagens sociológicas norte-americanas, notadamente da chamada "Escola de Chicago". Nos anos 1950, Guerreiro analisou o problema da mortalidade infantil como resultado de estruturas socioeconômicas subdesenvolvidas e criticou os programas de saúde pública que, a seu ver, estavam desarticulados do objetivo prioritário de industrialização.

Palavras-chave: História das Ciências Sociais no Brasil. Saúde Pública. Guerreiro Ramos. Departamento Nacional da Criança. Escola de Chicago. Desenvolvimento nacional.

\footnotetext{
*Doutor em Ciência Política pelo Intituto Universitário de Pesquisa do Rio de Janeiro (luperj), pesquisador titular e professor do Programa de Pós-Graduação em História das Ciências e da Saúde da Casa de Oswaldo Cruz (Fiocruz) - Brasil.E-mail: maio@coc.fiocruz.br

**Bacharel em Ciências Sociais pela Universidade Federal do Rio de Janeiro (UFRJ) e mestrando do Programa de Pós-Graduação em História das Ciências e da Saúde da Casa de Oswaldo Cruz (Fiocruz) - Brasil. E-mail: lopes_47@hotmail.com
} 


\section{From Chicago School to national developmentalism: health and nation in the thought of Alberto Guerreiro Ramos (1940-1950)}

\section{Abstract}

This paper explores the interface between Public Health and Social Sciences in Alberto Guerreiro Ramos' thought (1940-1950), in the light of his intellectual trajectory and the history of Social Sciences in Brazil. It shows how Health itself was a key-element for Guerreiro Ramos's interpretation about nation and the role of Social Sciences in the process of modernization. Starting his career in Brazilian government agencies, Guerreiro's first writings on Well-child care and Health were inspired by north-American sociological approaches, mainly derived from the so-called "Chicago School of Sociology". In the 1950s, Guerreiro Ramos accounted for health problems such as infant mortality in terms of "underdeveloped" social-economic structures and criticized Brazilian health programs he somehow considered detached from the country's main goal of industrialization.

Keywords: History of the Social Sciences in Brazil. Public Health. Guerreiro Ramos. Chicago School of Sociology. National development.

\section{Introdução}

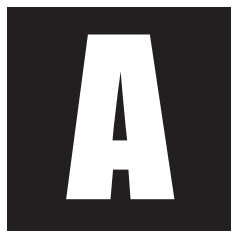

s décadas de 1940 e 1950 constituem um período importante da História das Ciências Sociais no Brasil. Envolvendo-se nos debates acerca de projetos nacionais, sociólogos e antropólogos dedicaram-se à análise das possibilidades de modernização do país e do papel que caberia a eles desempenhar (Vianna, 1997; Villas Bôas, 2006). As formulações acerca da ordem social que se projetava para o futuro - racionallegal, industrializada, igualitária - bem como a avaliação dos entraves à sua concretização estiveram balizadas pela revisão das interpretações abrangentes da sociedade legadas pelo pensamento social brasileiro, pelo 
apelo a novos padrões de cientificidade na abordagem do social e pelo processo em curso de institucionalização universitária das Ciências Sociais no país (Oliveira, 1995a; Vianna, 1997). Neste sentido, destaca-se, na década de 1930, a criação da Escola Livre de Sociologia e Política (ELSP) (1933), da Faculdade de Filosofia, Ciências e Letras da USP (1934) e da Faculdade Nacional de Filosofia da Universidade do Brasil (FNFi) (1939). A prática das Ciências Sociais se associou, nas décadas consecutivas, a empreendimentos internacionais de grande vulto, como o projeto UNESCO de relações raciais (Maio, 1997), e a centros de pesquisa, tais como: o Centro Brasileiro de Pesquisas Educacionais (CBPE) (1956) e o Centro Latino-Americano de Pesquisas em Ciências Sociais (CLAPCS) (1958). Nessas iniciativas, sobressaiu a vocação dos cientistas sociais como agentes da mudança (Villas Bôas, 2006).

Um capítulo que começa a ser explorado no desenvolvimento das Ciências Sociais no Brasil diz respeito à atuação de sociólogos e antropólogos em agências do Estado, provendo orientação técnico-científica para a intervenção social em setores tidos como fundamentais para o desenvolvimento do país, como o da saúde ${ }^{1}$. Com efeito, a ênfase em métodos e técnicas de pesquisa que garantissem a cientificidade daquelas disciplinas esteve por vezes acompanhada da preocupação em promover sua aplicação prática. O antropólogo Arthur Ramos, catedrático da FNFi, ao avaliar os problemas da Antropologia no Brasil, destacava a necessidade de reconhecimento da disciplina enquanto experiência científica indispensável às diferentes áreas de atuação social do governo (Ramos, 1948, p. 224). Em São Paulo, o sociólogo Emílio Willems afirmava que cientistas sociais deveriam ser mobilizados no encaminhamento técnico dos problemas do meio rural brasileiro, assegurando os meios adequados de sua transição

1 Trabalhos que buscaram traçar um quadro amplo da história dessas disciplinas no país privilegiaram a análise de suas práticas a partir de universidades e outras instituições culturais. Ver, por exemplo, Miceli (2001). 
para uma sociedade moderna (Lima; Maio, 2009). Um caso que assumiu relevância na área da saúde diz respeito ao Serviço Especial de Saúde Pública (SESP). Fruto da parceria dos governos brasileiro e norte-americano em 1942, o SESP empregou sociólogos e antropólogos brasileiros na Seção de Pesquisa Social criada em 1953 nos quadros da Divisão de Educação Sanitária. A Seção foi dirigida por José Arthur Rios, sociólogo com pós-graduação em Sociologia Rural nos Estados Unidos e coordenador da Campanha Nacional de Educação Rural no início dos anos 1950. Arthur Rios e sua equipe procuraram transmitir a médicos, educadores sanitários e visitadoras perspectivas socioantropológicas que possibilitassem uma ação mais eficiente dos serviços médicos-sanitários sobre as populaçõesalvo, marcadamente, segmentos de origem rural cujos arraigados hábitos sociais figuravam como entrave à mudança (idem).

A interface entre Ciências Sociais e Saúde Pública também é notória na produção intelectual de Alberto Guerreiro Ramos (1915 - 1982), sociólogo que iniciou carreira na burocracia do Estado, tendo integrado o corpo docente do curso de formação em puericultura do Departamento Nacional da Criança (DNCr) e o quadro de funcionários do Departamento de Administração do Serviço Público (DASP) no início dos anos 1940. Seus primeiros trabalhos tiveram a finalidade de informar sociologicamente a prática de técnicos nos campos da Saúde, da Puericultura e da Administração. Ao dar prosseguimento à sua reflexão sociológica na década de 1950, Guerreiro Ramos tratou igualmente de articular problemas sociais como a mortalidade infantil a uma perspectiva de desenvolvimento nacional segundo a qual a industrialização e o crescimento econômico alavancados pelo Estado constituíam as principais vias de transformação das condições sanitárias do país.

Este artigo tem por objetivo examinar os trabalhos de Guerreiro Ramos em torno da temática da saúde à luz de sua trajetória social e intelectual. Trata-se de analisar as implicações desses estudos em seu projeto político para a nação e em sua reflexão acerca da natureza e dos fins a se- 
rem perseguidos pelas Ciências Sociais no país. Será possível, deste modo, ampliar a compreensão acerca do posicionamento político e intelectual de Guerreiro Ramos e das polêmicas que travou no início da década de 1950, não apenas com cientistas sociais como Arthur Rios, mas também com médicos sanitaristas e puericultores. Neste sentido, sugere-se que a Saúde foi um elemento-chave acionado por Guerreiro no esforço de elaboração de interpretações acerca da construção da nação e dos dilemas que impediam sua inserção no mundo moderno.

Inicialmente, a trajetória intelectual de Guerreiro Ramos será apresentada, tendo como referencia sua incursão na área da Saúde (1943 1955). Em seguida, pontuam-se as principais características dos estudos sociológicos de Guerreiro relativos à Infância e à Saúde a partir das aulas que ministrou no DNCr. Estes trabalhos foram inspirados em abordagens sociológicas norte-americanas, notadamente da Universidade de Chicago. Finalmente, o trabalho analisará o crescente envolvimento do sociólogo com o problema da mortalidade infantil ao final da década de 1940 e suas consequências na formulação de um projeto de desenvolvimento para o país. A reflexão do sociólogo neste período foi marcada pelos diálogos que travou com médicos sanitaristas como Mário Magalhães da Silveira e cientistas sociais atuantes no setor Saúde, como José Arthur Rios.

\section{De Santo Amaro ao Distrito Federal}

Guerreiro Ramos nasceu em Santo Amaro da Purificação, cidade próxima a Salvador, numa família mulata das classes subalternas. Por intermédio de relações com famílias tradicionais baianas, ingressou no Ginásio da Bahia, instituição de ensino de grande prestígio à época (Maio, 1997). Na década de 1930, militou no integralismo e entrou em contato com o pensamento católico francês a partir das revistas Esprit e L'Ordre Noveau. Participou também do setor cultural do governo Landulfo Alves, 
então interventor da Bahia, trabalhando para seu irmão, Isaías Alves, criador da Faculdade de Filosofia da Bahia (Oliveira, 1995). O envolvimento em movimentos de cunho político e religioso facilitou a circulação de Guerreiro Ramos em ambientes da classe média baiana, onde escreveu crítica literária para jornais locais como O Imparcial, pertencente a simpatizantes do integralismo (Maio, 1997). ${ }^{2}$

No final de 1939, Guerreiro partiu para o Rio de Janeiro com bolsa do governo baiano para cursar Ciências Sociais na então Universidade do Brasil, integrando sua primeira turma. Criada em 1939, a organização da Faculdade Nacional de Filosofia (FNFi) resultou da articulação entre segmentos da Igreja Católica e o ministro da Educação Gustavo Capanema ${ }^{3}$. Conforme seu depoimento, Guerreiro Ramos foi indicado, ao término do curso, para ser professor assistente tanto da cadeira de Sociologia como da de Ciência Política, tendo sido, contudo, preterido por Luiz de Aguiar Costa Pinto e Victor Nunes Leal respectivamente (Guerreiro Ramos, 1995).

Em 1943, por indicação do diretor da FNFi, San Thiago Dantas ${ }^{4}$, Guerreiro Ramos se tornou professor da cadeira Problemas Econômicos e Sociais do Brasil no curso de Puericultura e Administração do Departamento Nacional da Criança (DNCr) (1943 - 1948), dedicando-se à reflexão sociológica sobre a puericultura, a mortalidade infantil, a delinquência juvenil

2 Dados de sua biografia estão em Oliveira (1995), Maio (1997), Azevêdo (2006) e Bariani Junior (2008). 3 Oliveira (1995a) observa que a instituição não associava ensino e pesquisa, carecendo ainda de perspectivas quanto à carreira universitária para os quadros que formava. No Rio, a primeira experiência de ensino das Ciências Sociais em nível superior ocorreu com a criação da Universidade do Distrito Federal em 1935 (Idem). No contexto de agitações políticas dos anos 1930, o projeto da universidade, que lhe conferia autonomia frente ao governo federal, chocou-se com interesses da Igreja e do ministro Capanema, que encerrou suas atividades em 1939 (Oliveira, 1995a; Almeida, 2001).

4 Formado na Faculdade Nacional de Direito, onde passou a lecionar, Francisco Clementino de San Thiago Dantas militou no integralismo na década de 1930, afastando-se do movimento em 1938, por ocasião da preparação de um levante para depor o presidente Vargas (Abreu, 2001). 
e a medicina popular (Oliveira, 1995). Neste ano, foi ainda contratado interinamente para o cargo de técnico em administração no DASP, em um momento em que o órgão buscava racionalizar a ação do poder estatal (Maio, 1997). Permanecendo até 1951 no DASP, Guerreiro publicou na Revista do Serviço Público diversos artigos sobre padrão de vida, orçamento familiar e classes sociais, analisando também obras de sociólogos como Émile Durkheim, Max Weber, William I. Thomas e Karl Mannheim. Enquanto burocrata e intelectual, Guerreiro teve que desenvolver seu lado acadêmico conquistando espaços ao funcionário (Oliveira, 1995, p.14)5.

O início da década de 1950 esteve marcado, na trajetória do sociólogo, pelo envolvimento em intensa atividade intelectual. Integrou-se ao Teatro Experimental do Negro, debatendo com outros intelectuais a questão do negro e das relações raciais na sociedade brasileira (Maio, 1996). Em 1950, valendo-se da experiência no DNCr, Guerreiro escreveu uma série de artigos para o jornal A Manhã expondo sua abordagem sociológica sobre a mortalidade infantil no país e avaliando o desempenho do governo e dos programas de saúde frente aos problemas sanitários. Neste período, aproximou-se de médicos sanitaristas como Mário Magalhães da Silveira, igualmente crítico das ações governamentais na área da Saúde (Guerreiro Ramos, 1955).

No segundo governo de Vargas, Guerreiro participou da Assessoria da Casa Civil, o que teria contribuído fortemente para a sua compreensão do Brasil (Oliveira, 1995). Tornou-se ainda membro do Instituto Brasileiro de Economia, Sociologia e Política (IBESP), futuro Instituto Superior de Estudos Brasileiros (ISEB). Formado por intelectuais como Hélio Jaguaribe, Ignácio Rangel e Roland Corbisier, sua pauta de discussões centrou-se em questões como o nacionalismo e o subdesenvolvimento brasileiro (Schwartzman, 1983).

5 Para uma análise da produção intelectual de Guerreiro Ramos associada à sua passagem pelo DASP, ver Bariani Junior (2008, p. 20-48). 
Em 1953, Guerreiro participou ainda, como presidente da Comissão de Estruturas Nacionais e Regionais, do II Congresso Latino-Americano de Sociologia. Na ocasião, o sociólogo se envolveu no debate referente à natureza e ao papel das Ciências Sociais no Brasil, expondo pontos de vista polêmicos que deram origem à Cartilha brasileira do aprendiz de sociólogo (1954), livro dedicado a Mário Magalhães. Em 1955, foi publicado no México Sociologia de la Mortalidad Infantil, obra na qual o sociólogo reuniu parte considerável de seus artigos anteriores sobre Saúde Pública. Enfocando os elos entre as condições sanitárias de diferentes países e o respectivo grau de desenvolvimento da suas estruturas socioeconômicas (Guerreiro Ramos, 1955a), o livro foi um marco importante das investigações de Guerreiro na área da Saúde.

\section{Guerreiro Ramos e o Departamento Nacional da Criança}

O DNCr veio à luz por decreto-lei em 1940, associado a um movimento mais amplo de incorporação de políticas sociais dentro das funções do Estado a partir da Revolução de 30. Data deste período a criação do Ministério da Educação e Saúde Pública (MESP) e do Ministério do Trabalho, Indústria e Comércio, que acompanharam o fortalecimento do Estado por meio do corporativismo e da centralização administrativa (Fonseca, 1990). Os planos traçados pelo Departamento Nacional da Criança (DNCr) para a proteção da infância faziam eco à preocupação oficial com a construção da nação e a valorização do trabalhador. A criança era um trabalhador em potencial e representava o futuro da nacionalidade, devendo ter a sua saúde e seu bom desenvolvimento físico e mental assegurados.

Antes dos anos 1930, instituições privadas haviam sido as principais responsáveis pela assistência e proteção materno-infantil (Fonseca, 1990; Pereira, 1992). Dentre elas, destacou-se o Instituto de Proteção e Assistência à 
Infância do Rio de Janeiro, órgão de moldura filantrópica que, no início do século XX, havia instalado ao menos vinte filiais pelo país (Pereira, 1992). A criação do DNCr, por sua vez, esteve relacionada à pressão, junto ao governo, de um dos principais membros daquela instituição, Olinto de Oliveira, puericultor que se destacou na defesa de uma rede de proteção maternoinfantil de cobertura nacional. Oliveira havia se inserido na burocracia estatal em 1930 ao assumir a direção da Inspetoria de Higiene Infantil (Idem). A Conferência Nacional de Proteção à Infância, convocada por Getúlio Vargas em 1933, elevou o órgão à Divisão de Amparo à Maternidade e à Infância do Departamento Nacional de Saúde. A criação do DNCr, em 1940, significou maior autonomia administrativa para os serviços de proteção infantojuvenil, que ficaram subordinados diretamente ao ministro da Educação e Saúde Gustavo Capanema. Os técnicos do DNCr buscaram o auxílio das elites locais, da classe média e da Igreja em suas campanhas nacionais em prol da criança, o que pode ser atribuído à carência de recursos públicos para viabilização de seus projetos (Fonseca, 1990; Pereira, 1992).

O DNCr se propunha a atuar principalmente em articulação com os municípios por meio de suas instituições de assistência privadas e das autoridades locais. Um corpo técnico-administrativo deveria ser formado tendo em vista a orientação e a fiscalização desses atores, que poriam localmente em prática os serviços conforme as determinações do programa do DNCr, concentrado no combate à mortalidade infantil, na assistência à nutrição materna e infantil, na propaganda da alimentação "cientificamente orientada", na promoção da higiene pré-natal, na assistência ao parto e na educação sanitária de crianças e gestantes, notadamente aquelas pertencentes aos estratos sociais mais baixos ${ }^{6}$. Para tanto, o

6 Entre os planos postos efetivamente em prática pelo DNCr até 1945, destacam-se a realização de inquéritos sobre mortalidade infantil, sobre menores abandonados e delinquência infantil; censo dos estabelecimentos de assistência à maternidade, à infância e à adolescência; instrução sobre a execução de serviços; estudos de projetos de postos de puericultura e hospitais infantis (Fonseca, 1990). 
DNCr organizou, a partir de 1942, cursos de especialização, divididos em três modalidades: Curso de Puericultura e Administração, voltado para o pessoal que dirigiria os serviços oficiais; Cursos de Aperfeiçoamento e Especialização de Médicos, dedicados ao aprimoramento profissional na área de puericultura; e os Cursos de Treinamento de Pessoal Auxiliar, que formariam técnicos auxiliares (Pereira, 1992).

Por ocasião da aula inaugural do primeiro curso de Puericultura e Administração em 1943, o DNCr publicou em seu boletim de notícias nota destacando a necessidade de preparar técnicos que não poderiam ser meros sanitaristas, mas deve[riam] ser puericultores, isto é, médicos conhecedores, igualmente, dos problemas da clínica e da higiene infantil, como da assistência social e dos fenômenos econômicos (Boletim Trimensal do Departamento Nacional da Criança, n.16, p.2). A aula esteve a cargo de San Thiago Dantas, então diretor da Faculdade Nacional de Filosofia (FNFi) e professor de Direito, que esboçou para os discentes do curso o panorama geral dos problemas econômicos e sociais do Brasil (idem). Na solenidade de encerramento das aulas, que formou 16 puericultores, Dantas também discursou, desta vez sobre A Importância da Sociologia na formação dos Médicos Puericultores (idem, n.20, p.4).

San Thiago Dantas foi o responsável pela indicação de Guerreiro Ramos para professor da cadeira de número 7, Problemas Econômicos e Sociais do Brasil. Guerreiro atuou na formação de seis turmas de médicos puericultores entre 1943 e 1948. Sugeriu que sua cadeira tivesse o nome alterado para Sociologia e Economia ou Sociologia e Economia Aplicadas ao Brasil, destacando ainda a necessidade de uma cadeira própria reservada à Pesquisa Social para o médico puericultor (Guerreiro Ramos, 1944, p.14). As lições de Guerreiro Ramos representaram o esforço de levar ao conhecimento daqueles profissionais de saúde um approach sociológico dos problemas relativos à infância no Brasil - problemas candentes na agenda 
do DNCr, como o elevado índice de mortalidade infantil e a denominada delinquência juvenil. Em um movimento de legitimação da Sociologia, Guerreiro procurou demonstrar o status científico da disciplina bem como sua aplicabilidade ou caráter prático no campo da Puericultura.

Os primeiros trabalhos de Guerreiro Ramos no DNCr estiveram marcados por abordagens sociológicas norte-americanas, gestadas predominantemente na Universidade de Chicago nas décadas de 1920 e 1930. Guerreiro se concentrou na divulgação dos estudos cujos objetos dialogavam diretamente com a agenda de questões do DNCr, esforçando-se por indicar que a Sociologia Científica não era uma tagarelice de homens ociosos (Guerreiro Ramos, 1944, p.09). O sociólogo conferiu destaque às pesquisas de Robert Park, Ernest Burgess, Frederick McKenzie, Clifford Shaw e Henry McKay, centrados nos denominados problemas urbanos, como o crime, o divórcio, a delinquência juvenil, a prostituição e as gangues, grande parte deles tendo sido realizada sob a orientação de Park e Burgess (Coulon, 1995; Valladares, 2005) ${ }^{7}$.

A aproximação de Guerreiro Ramos a práticas sociológicas norteamericanas ocorreu por meio dos manuais e artigos que Donald Pierson, sociólogo formado em Chicago, vinha divulgando a partir de sua ativi-

7 O Departamento de Ciências Sociais da Universidade de Chicago, criado em 1892, foi o mais influente dos Estados Unidos, ao menos até os anos 1940 (Coulon, 1995; Peixoto, 2001). Sua abordagem marcadamente empírica esteve inicialmente associada ao movimento de reforma social das classes médias de orientação protestante. No fim do século XIX, o boom demográfico e o crescimento metropolitano de Chicago decorrentes da industrialização fizeram da cidade um verdadeiro "laboratório social" para o exame de problemas sociais como o crime e a incorporação de imigrantes (Coulon, 1995; Valladares, 2005). Dentre as obras aludidas com frequência por Guerreiro neste período estão: Introduction to the Science of Sociology, de Robert Park e Ernest Burgess; Brothers in Crime - The Natural History of a Delinquent Career e The JackRoller, a Delinquent Boy's Own Story, de Clifford Shaw e Social Pathology, de Lawrence Guy Brown (Guerreiro Ramos, 1944; 1944a; 1945; 1947). 
dade docente na Escola Livre de Sociologia e Política (ELSP) e em cursos itinerantes pelo Brasil ${ }^{8}$. Guerreiro participou do Curso de Sociologia ministrado por Pierson no Rio de Janeiro e organizado pelo DASP em 1942 (Maio, 1997). O programa do curso, realizado em 11 conferências, conferiu destaque às seguintes questões: As ciências sociais no mundo de hoje; O estudo da Sociedade; Métodos e técnicas de pesquisa nas Ciências Sociais; Desenvolvimento de uma atitude científica e O crescimento da cidade grande (Pierson, 1942).

Com efeito, neste período, a argumentação de Guerreiro Ramos acerca da cientificidade da Sociologia inspirou-se em concepções que Pierson esforçava-se por transmitir. À semelhança do norte-americano (Pierson, 1962 [1945], pp.5-8), Guerreiro afirmou que a Sociologia havia se constituído como Ciência ao abandonar o período das escolas em que se acreditava na existência de uma sociologia francesa, de uma sociologia alemã e de uma sociologia norte-americana, livrando-se de sistemas filosóficos pessoais e instituindo a pesquisa social (Guerreiro Ramos, 1944, p.15).

Em suas lições no DNCr, Guerreiro Ramos propôs uma interpretação do problema da delinquência juvenil à luz do fenômeno da desorganização social, categoria avançada por Robert Park no livro Introduction to the Science of Sociology (1921) - a um só tempo manual didático e

8 Donald Pierson cursou pós-graduação em Chicago, investigando as relações raciais na Bahia, sob a orientação de Robert Park, sociólogo de relevo nos anos 1920 e 1930. Contratado pela ELSP em 1939, Pierson atuou na organização institucional dos cursos de Ciências Sociais, estabelecendo a primeira pós-graduação no país em 1941; divulgou livros, promoveu periódicos especializados e realizou cursos itinerantes em outros estados. Atuou diretamente na formação de uma geração de cientistas sociais brasileiros, como Oracy Nogueira, Florestan Fernandes, Mário Wagner Vieira da Cunha, Darcy Ribeiro e Juarez Brandão Lopes (Corrêa, 1987). Em contraste com o projeto inicial da ELSP elaborado pelas elites paulistas, visando a formação de quadros técnicos em administração, Pierson buscou imprimir à instituição uma feição mais acadêmica, treinando sociólogos profissionais (Limongi, 2001). 
programa de pesquisa para os estudantes de ciências sociais da Universidade de Chicago nos anos 1920 e 1930 (Chapoulie, 2001, p. 158). Em linhas gerais, a perspectiva de Park e Burgess contrastava o controle social existente no ambiente rural - isto é, um universo marcado pelas relações primárias, face a face, com forte coesão e solidariedade moral entre os indivíduos - com o afrouxamento dos laços sociais e o anonimato das relações característicos da vida urbana. A cidade, com sua diversidade de estilos e valores sociais, conduziria muitas vezes à desintegração dos laços morais e ao desajustamento de jovens e crianças, que não poderiam mais ser socializados da forma unívoca e coesa peculiar ao ambiente rural (Chapoulie, 2001, pp. 111/ 258; Pierson, 1962 [1945], pp. 145-146). Nas palavras de Guerreiro, o membro da comunidade rural é mais socializado que o urbanita. No mundo rural, a família é um centro de gravidade poderoso, verdadeira célula da comunidade (Guerreiro Ramos, 1944, p. 36).

Destarte, para Guerreiro Ramos, uma sociologia da cidade indicaria que não se deve dar excessiva ênfase ao aspecto biológico de problemas como a delinquência juvenil, sendo estes eminentemente sociais (idem). Uma criança nascida em áreas de desorganização social aprenderia como naturais os modelos que lhe [eram] apresentados, não estando em seu poder escolher os modelos aprovados socialmente [ou] perceber que os que adota[va] [eram] prejudiciais à sociedade (idem). Note-se que a ênfase de Robert Park e Ernest Burgess sobre o papel desempenhado pela socialização no ambiente urbano, no que diz respeito à conformação do comportamento desajustado do menor infrator, esteve associada à luta contra concepções estritamente biológicas, de corte racial, sobre as causas da delinquência e do crime, em vigor nos Estados Unidos nas primeiras décadas do século XX (Coulon, 1995; Chapoulie, 2001; Valladares, 2005). Os modernos instrumentos de pesquisa elaborados pelos sociólogos de Chicago tornariam possíveis a delimitação e classificação das áreas que 
compunham os centros urbanos brasileiros, indicando a localização espacial de seus principais problemas ${ }^{9}$. Para o sociólogo, o início da ação profilática sobre o comportamento desviante residiria na reestruturação de ambientes como cortiços, pardieiros, vielas onde a população se adensa em espaços insuficientes (Guerreiro Ramos, 1944, p. 41).

O conhecimento sociológico poderia ser igualmente aplicado na terapêutica dos desajustamentos psicossociais. Tendo como referência estudos de Lawrence Guy Brown, como Social Pathology, e de Clifford Shaw, como Brothers in Crime, The Natural History of a Delinquent Career, Guerreiro propôs o estabelecimento de Clínicas Sociológicas do Comportamento, local em que o puericultor empregaria técnicas sociológicas como a história de vida. Recurso de pesquisa peculiar a Chicago, consagrado desde a obra de Thomas acerca dos camponeses poloneses (Chapoulie, 2001), a história de vida, no caso clínico, seria realizada a partir de relatos dos "desajustados" e de dados de sua vida cotidiana, reunidos por meio de cartas, diários, depoimentos de amigos, de familiares, etc., de modo que o puericultor pudesse conduzir sua reeducação (Guerreiro Ramos, 1944a). Note-se que Lawrence Guy Brown e Clifford Shaw haviam estudado na Universidade de Chicago sob a orientação de Burgess. (Chapoulie 2001, p.262) observa que, ao término da pós-graduação, Shaw passou a trabaIhar no departamento de sociologia do Institute of Juvenile Research, órgão governamental (Estado de Illinois) destinado ao tratamento de jovens delinquentes, onde realizou a maior parte de suas pesquisas.

O instrumental técnico e metodológico de Chicago também poderia ser aplicado à outra questão basilar da agenda do $\mathrm{DNCr}$, o elevado coefi-

9 Guerreiro observava que era preciso confrontar os esquemas explicativos acerca do desenvolvimento dos espaços urbanos de Chicago com a realidade das cidades brasileiras. O sociólogo tinha em mente o modelo de expansão urbana por meio de zonas concêntricas, proposto por Ernest Burgess (Chapoulie, 2001). 
ciente de mortalidade infantil no país ${ }^{10}$, por meio da delimitação espacial de sua ocorrência e concentração. Ainda que sem desenvolver análises sistemáticas sobre o tema nesses primeiros trabalhos, Guerreiro associou o fenômeno às classes com baixo padrão de vida, em que predominavam a falta de instrução, o excesso de trabalho, a desnutrição, a falta de assistência médica e a habitação em comum em ambientes anti-higiênicos (1944, p.41). Tratava-se de intervir em áreas específicas das cidades que se apresentavam como focos de doença. Aos serviços de saúde caberiam inúmeras medidas, tais como: construção em massa de habitações higiênicas, [...] casas maternais, restaurantes populares, escolas, parques infantis [...] cada um destes aspectos devendo ser considerado em todos os seus detalhes e minúncias [sic], nas áreas de desorganização social (Guerreiro Ramos, 1945, p. 13).

Guerreiro Ramos propôs ainda a profilaxia do comportamento infantil por meio de escalas sociométricas, a serem aplicadas em escolas com o intuito de sondar atitudes e verificar desvios potenciais (Guerreiro Ramos, 1944a). Neste sentido, a Divisão de Proteção Social da Infância do DNCr deveria criar as escalas sociométricas convenientes à criança brasileira. A atividade clínica exigiria o trabalho conjunto de médicos, psicólogos, sociólogos, psicólogos sociais e pesquisadores sociais. Segundo Guerreiro,

Temos mais de dez Faculdades de Filosofia com cursos de ciências sociais. A oportunidade que o Departamento Nacional da Criança [...] abre àqueles que se dedicam às ciências sociais é a de tomar contato com os fenômenos de que tratam suas disciplinas não através de livros, mas de fato. Assim poderíamos descolonializar [sic] os nossos processos de pesquisa social concernentes à criança, descobrindo técnicas próprias e contribuindo para criar no país um ambiente científico genuíno no terreno das ciências sociais, ligado ao problema da criança, ambiente onde passassem a ser ridículas as ati-

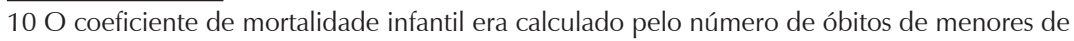
um ano para mil nascidos vivos no período de um ano. 
tudes livrescas e as inoperantes demonstrações de erudição, vício tão comum numa certa casta de pseudo-cientistas que nada fazem senão importar teorias alheias para embasbacar o indígena desprevenido e de boa fé... (idem, p. 326).

O estabelecimento de uma Sociologia genuinamente científica no Brasil implicava a definição de seus contornos nacionais. O saber-fazer da pesquisa empírica que cientistas sociais como Donald Pierson vinham divulgando deveria ser valorizado enquanto movimento inicial de exploração da realidade social do país. Somente a partir deste ponto seria possível o trabalho crítico de construção de um arcabouço metodológico autóctone. No quadro nacional de ensino das Ciências Sociais nas Faculdades de Filosofia, São Paulo constituía exceção pelo pioneirismo da ELSP na organização de atividades no setor da pesquisa sociológica (Guerreiro Ramos; Garcia, 1949, pp. 09 - 10). Neste sentido, Guerreiro atribuía a atitude livresca ${ }^{11}$ a professores universitários que, pela falta da prática em pesquisa, permaneciam distanciados dos fatos conformadores da realidade nacional. $\mathrm{O}$ trecho acima também indica o esforço característico do professor do DNCr em expandir o espaço de atuação profissional dos cientistas sociais para além da vida universitária, apontando funções técnicas que poderiam assumir no âmbito do Estado. Assim, em contraste com Pierson, para quem a carreira do sociólogo profissional estaria pautada pela atividade de pesquisa de escopo acadêmico (Pierson, 1962 [1945], pp. 26 - 29), Guerreiro propunha

11 Note-se que a expressão também foi utilizada por outros cientistas sociais neste período, como foi o caso do antropólogo Arthur Ramos, então professor da Faculdade Nacional de Filosofia. Tratava-se de assinalar o que se percebia como falta de rigor metodológico nas interpretações generalizantes sobre a sociedade brasileira. Assim, Ramos observava que, no campo da Antropologia, a superação de hipóteses de fundo livresco, literatóide, em direção a formulações de cunho científico, só poderia ocorrer mediante a prática de pesquisa sistemática nas universidades do país (Ramos, 1948, p.215). Para análises sobre a busca por cientificidade nas Ciências Sociais nos anos 1930 e 1940, que implicou a crítica ao denominado ensaísmo, ver Santos (2002); Oliveira (1995a); Lima (1998) e Botelho (2010). 
que aquela prática se ampliasse ao aconselhamento e à orientação junto a órgãos públicos, pondo o cientista social diretamente em contato com os problemas sociais do país (Guerreiro Ramos, 1944a).

A partir de meados da década de 1940, a atenção de Guerreiro Ramos esteve centrada fundamentalmente no aprofundamento das investigações acerca da relação entre a saúde das populações e as condições socioeconômicas do país. O sociólogo passou a considerar a necessidade de pesquisas acerca da mortalidade infantil de proporções mais amplas que os inúmeros estudos monográficos até então realizados sob patrocínio do DNCr. Isto implicava a análise dos aspectos macro-sociais e econômicos do problema a partir de dados referentes a todo território nacional.

\section{Saúde e desenvolvimento}

A análise sistemática de Guerreiro Ramos acerca do fenômeno da mortalidade infantil no Brasil significou a substituição das abordagens teóricas e metodológicas inspiradas na sociologia urbana de Park, Burgess e Shaw em favor de uma perspectiva mais preocupada em detectar os contornos nacionais do problema, indicando sua origem na estrutura socioeconômica do país. A solução do problema implicava a elevação dos padrões de vida das massas mediante processo de industrialização capitaneado pelo Estado. À luz de um projeto visando a autarquia econômica do país, as medidas de assistência e de intervenção diretas na área da saúde pública passaram a ser desacreditadas em função dos elevados gastos públicos e da pouca eficácia que significavam em um contexto nacional de subdesenvolvimento. Com efeito, Guerreiro passou a afirmar que os profissionais de saúde do Estado se concentravam excessivamente em ações curativas imediatas, faltando-Ihes a orientação sociológica capaz de explicitar as relações entre a saúde da população e suas condições de vida. 
A partir do final da Segunda Guerra Mundial, a temática do desenvolvimento esteve na pauta de discussões dos foros internacionais. Tendo os países industrializados como parâmetro, esforços multilaterais foram envidados no sentido de implementar programas visando à superação da pobreza (Oliveira, 1995a; Campos, 2006). No caso da saúde, a concepção de um ciclo vicioso da doença e da pobreza, conceito este inspirado no sociólogo sueco Gunnar Myrdal, ganhou visibilidade como chave explicativa do atraso dos países subdesenvolvidos. As condições sanitárias precárias afetavam o desempenho econômico da população, que, por sua vez, perpetuava seu estado de pobreza (Hochman, 2009). Esta visão do ciclo vicioso orientou, por vezes, a ação de organismos internacionais como a OPAS e a OMS (Campos, 2006).

Guerreiro Ramos pôde explorar os vínculos entre índices de saúde e o quadro socioeconômico da população brasileira a partir de sua experiência no Departamento de Administração do Serviço Público em meados dos anos 1940. Na ocasião, o sociólogo analisou pesquisas que tratavam sobre padrão de vida, níveis de vida, custo de vida, renda nacional, poder aquisitivo e hábitos de consumo. A compilação das despesas de famílias e de indivíduos de diferentes classes sociais - por meio de indicadores como saúde, alimentação, educação e habitação - traçavam um perfil das condições de vida da população ${ }^{12}$. Na Revista do Serviço Público, periódico oficial do DASP, Guerreiro Ramos escreveu aos técnicos de administração sobre a relevância daqueles estudos para a elaboração de políticas públicas. Nas palavras do sociólogo, eles formavam uma espécie de levantamento topográfico do consumo popular, sem o qual os serviços

12 No segundo governo Vargas, Guerreiro dirigiu uma pesquisa sobre padrão de vida na sociedade brasileira sob patrocínio da Comissão Nacional de Bem-Estar Social, órgão vinculado ao Ministério do Trabalho, Indústria e Comércio (Maio, 1997, p.139). 
sociais de massa não poder[iam] atingir a plenitude de suas possibilidades de eficiência (Guerreiro Ramos, 1947, p.136). Afirmando a falta de empreendimentos desta natureza no Brasil, o sociólogo observou o pioneirismo de São Paulo, cidade em que foram realizadas as primeiras pesquisas sobre padrão de vida nos anos 1930, conduzidas pelos cientistas sociais norte-americanos Horace Davis e Samuel Lowrie ${ }^{13}$.

No intuito de sensibilizar a opinião pública, Guerreiro Ramos publicou artigos em jornais de grande circulação, expondo a variação dos índices de saúde conforme a inserção dos indivíduos nas diferentes classes sociais. O sociólogo argumentava que o baixo padrão aquisitivo do operariado urbano e dos trabalhadores rurais tinha como consequência imediata um baixo padrão educacional, alimentar e habitacional, de modo que o elevado coeficiente de mortalidade infantil se concentrava naqueles segmentos. A distribuição desigual da riqueza entre grupos sociais, e entre as diferentes regiões do país, incidia diretamente, portanto, sobre as elevadas taxas de mortalidade infantil no país.

No entanto, na opinião do sociólogo, seria ingênuo pensar num distributismo avançado como alternativa viável à questão nacional (Guerreiro Ramos, 1950, p. 3). O capitalismo brasileiro, cuja configuração histórica remetia ao período colonial, era incipiente. A análise da renda nacional indicava que sua divisão per capita seria insuficiente para atender aos níveis mínimos de subsistência dos brasileiros. Índices de saúde como a mortalidade infantil espelhavam, deste modo, uma fase específica da evolução econômica e social do país, caracterizada pela concentração da maior parte de sua população ativa em atividades primárias como a agricultura e pela

13 Integrantes da primeira equipe docente da Escola Livre de Sociologia e Política (ELSP), Davis e Lowrie foram pioneiros na utilização de instrumental estatístico em pesquisa social no país. As investigações mobilizaram parte do alunado do curso de Sociologia e Política, fato que se coadunava com a proposta inicial da ELSP de formação científica de elites técnicas que pudessem auxiliar a área de planejamento governamental (Del Vecchio; Diéguez, 2008). 
utilização de técnicas rudimentares na esfera do trabalho, que implicava grande dispêndio de esforço humano (Guerreiro Ramos, 1950, p. 2). A noção de "fase" servia para enfatizar o caráter dinâmico de toda estrutura socioeconômica, de modo que a natureza de seus problemas sociais corresponderia à configuração particular que assumia em um dado momento de seu desenvolvimento histórico (Guerreiro Ramos, 1955a, p. 14) ${ }^{14}$.

O processo de industrialização alavancado pelo Estado constituía a via fundamental para a solução dos problemas de saúde. Para Guerreiro, a industrialização traduzia-se, mais precisamente, no aperfeiçoamento dos métodos de exploração dos recursos naturais disponíveis e na elevação da capacidade produtiva do homem brasileiro, de modo a viabilizar a racional distribuição dos resultados dos esforços de cada homem entre os que cooperam no processo de produção (Guerreiro Ramos, 1951, p. 25). Ainda que tais medidas tenham sido por vezes associadas à promoção de uma democracia substantiva, visando à garantia de condições básicas de vida a toda população - o que Guerreiro denominou democracia econômica (Guerreiro Ramos, 1945, p.15) -, não há, no período considerado de sua produção intelectual, sinais de análises mais detidas sobre o processo propriamente político que pudesse efetivar a distribuição da riqueza ${ }^{15}$. O sociólogo obser-

14 A associação entre o processo de desenvolvimento e a noção de "fase", cuja elaboração é atribuída ao sociólogo alemão Carl Müller-Lyer, é abordada em Bariani Júnior (2008).

15 No contexto intelectual dos anos 1950, caracterizado pelo relevo conferido à ação governamental tecnicamente informada no processo de modernização econômica, é possível estabelecer um contraponto com o pensamento de autores como Celso Furtado, para quem a questão da democracia política esteve intimamente associada ao problema do desenvolvimento (Cepêda, 2001). A participação política dos segmentos populares, no marco das regras do jogo democrático, foi compreendida por esse autor como importante instrumento de pressão para o aumento da renda dos trabalhadores, o que garantiria, por sua vez, a própria continuidade do processo de crescimento econômico e desenvolvimento tecnológico (idem). Luiz Werneck Vianna observa que a ênfase de Guerreiro Ramos no protagonismo do Estado alimentava-se da crença da não-espontaneidade do desenvolvimento, reconhecida a incapacidade dos interesses em ação na sociedade civil para superar os impasses à modernização e à aceleração econômica (1947, p.197). 
vava que, por muito tempo, o desenvolvimento do país [teria] que ser obtido à custa do pauperismo ou de baixos salários (Guerreiro Ramos, 1950, p.3).

O diagnóstico elaborado por Guerreiro Ramos a respeito da mortalidade infantil significou a crítica às medidas preconizadas pelos puericultores atrelados ao Estado, como a criação em massa de maternidades e de postos de puericultura pelo território nacional. Não atacando o problema da mortalidade infantil em sua raiz estrutural, os gatos com serviços de saúde e assistência infantil acabavam por comprometer o orçamento da União com ações perfunctórias e de resultados passageiros. Em outros termos, Guerreiro propunha a redução máxima de empreendimentos de cunho filantrópico de modo a priorizar o investimento público em políticas mais abrangentes de transformação das condições de alimentação, habitação, educação e trabalho:

[...] não hesitamos em afirmar que não deve interessar ao Estado, senão em última instância, prestar assistência médica a populações que não possam ser recuperadas economicamente. Dar a uma população desajustada, a habitantes de favelas, por exemplo, assistência médica e social, sem Ihes dar, por intermédio de outros serviços, possibilidade de reabilitação profissional e, portanto, meios de subsistência, alimentação, habitação e educação, é permanecer na estaca zero (Guerreiro Ramos, 1948, p.1).

A análise do sociólogo era partilhada, em linhas gerais, por um grupo de médicos sanitaristas que vinha refletindo criticamente sobre os programas de saúde, buscando igualmente articulá-los a um projeto de desenvolvimento socioeconômico. Guerreiro Ramos teria se aproximado do grupo em 1950 (Guerreiro Ramos, 1955). Os sanitaristas em questão eram Mário Magalhães da Silveira, Almir de Castro e Pedro Borges. Tendo feito o curso de higiene e saúde pública no Instituto Oswaldo Cruz, MagaIhães logo ingressou nos quadros do Departamento Nacional de Saúde. A partir da criação do Ministério da Saúde, em 1953, passou a colaborar di- 
retamente com os ministros da pasta, tendo sido um dos principais articuladores das críticas dirigidas às políticas de Saúde do país nos anos 1940 e 1950 (Escorel, 2000). Pôde ainda expor seus pontos de vista por meio de aulas e palestras em cursos promovidos pela Comissão Econômica para a América Latina (Cepal) ${ }^{16}$ e pelo ISEB nos anos 1950. Almir de Castro foi responsável pela direção do Serviço Nacional da Peste do Ministério da Educação e Saúde de 1942 a 1954, quando deixou o cargo para assumir a direção-executiva da Capes (Ferreira; Moreira, 2003). Ao exercer o cargo de Delegado Federal de Saúde, Pedro Borges, médico interessado em estudos envolvendo produção de alimentos e deficiência alimentar, havia sido chefe da Seção de Pesquisas Sociais e Educação Alimentar do Instituto de Nutrição da Universidade do Brasil em 1946, trabalhando ao lado de Josué de Castro (Bizzo; Lima, 2009).

O alvo principal das críticas destes sanitaristas encontra-se no trabalho desenvolvido pelo Serviço Especial de Saúde Pública (SESP), órgão criado em 1942 a partir de uma parceria entre os governos brasileiro e norte-americano. Servindo inicialmente aos esforços de guerra em áreas estratégicas, ele continuou suas atividades no pós-guerra em grande medida devido ao apelo que sua ação sanitária teve para os projetos de desenvolvimento regional. O programa do SESP incluía a promoção de saneamento, serviços médico-hospitalares e educação sanitária centrada nas populações rurais. Se as doenças eram efeito da ignorância e dos maus hábitos de alimentação e higiene da população, investimentos em ações pedagógicas, conhecimento técnico e moderna infraestrutura sanitária poderiam reverter

16 A Cepal foi fundada em 1948, com sede em Santiago, Chile, por iniciativa das Nações Unidas. Nesse período, o órgão pôs em relevo, como estratégia para o desenvolvimento dos países latino-americanos, a industrialização via substituição de importações, o fortalecimento do mercado interno e a participação ativa do Estado na organização da esfera econômica (Oliveira, 1995a). 
este quadro, de modo que a melhoria progressiva das condições sanitárias favoreceria a superação do atraso do país (Campos, 2006).

Guerreiro Ramos e Mário Magalhães da Silveira procuraram inverter a ordem dos termos da relação saúde-desenvolvimento, presente na noção de ciclo vicioso adotada pelo SESP. Magalhães afirmava que a saúde de qualquer coletividade dependia da produtividade média de seus trabalhadores. O médico assinalava que, historicamente, as condições de saúde do homem e a duração média de vida haviam progredido conforme se substituía gradativamente a energia muscular na esfera da produção pela utilização de combustíveis sólidos, líquidos e gasosos (Magalhães, 1948; 2008, p. 39). Ou seja, a diminuição do desgaste humano ocorreria mediante o incremento tecnológico dos meios de exploração da natureza, o que seria traduzido ainda em economia de tempo e liberação da força de trabalho para atividades técnicas e científicas. Estas, por sua vez, só tendiam a reforçar a linha do progresso. Era possível verificar os resultados nas nações industrializadas, nas quais maiores disponibilidades de energia por habitante [eram acompanhados por] menores coeficientes de mortalidade geral, mortalidade infantil e maior vida média (Magalhães, 1948). Nessa explicação, que remete a um modelo marxista genérico difundido no período (Cepêda, 2001), os indicadores de saúde espelhavam a ordem socioeconômica global.

A partir de tal perspectiva, Magalhães teceu duras críticas ao SESP que, a seu ver, abordava a Saúde Pública como problema fundamentalmente técnico, ignorando suas dimensões socioeconômicas. Guerreiro Ramos e Magalhães colocaram em jogo, por vezes, os pressupostos da atuação do SESP, que seriam inadequados ao contexto brasileiro em função da inspiração norte-americana. O funcionamento do órgão segundo padrões norte-americanos exigia custos que iam além das condições financeiras do Estado, o que significava, para Magalhães, a impossibilidade de ampliar seus 
serviços à maior parte da população brasileira (Magalhães, 2008). Julgavase erroneamente que a complexa e sofisticada organização sanitária dos países desenvolvidos deveria ser aplicada à realidade do país de modo a reproduzir as boas condições de saúde observadas naquelas nações e abrir caminho ao progresso social. Para Guerreiro e Magalhães, ao procederem de tal modo, confundiam-se efeitos e causas. Nas palavras do sociólogo,

[...] as instituições administrativas não tem nenhum poder mágico ou imanente de resolver os problemas. Elas só rendem em função umas das outras e do meio nacional onde atuam. É inócuo transplantá-las de um país para outro de condições radicalmente diferentes. Os organizadores de nossos sistema de assistência médico-sanitária não compreenderam que os modelos norte-americanos só teriam eficácia em nosso país se a sua estrutura econômica e social tivesse atingido uma fase mais adiantada de desenvolvimento (Guerreiro Ramos, 1951, p. 40).

Deste modo, para Guerreiro Ramos, caberia ao cientista social conferir senso sociológico aos órgãos governamentais, ou seja, corrigir sua inclinação por resultados imediatos em detrimento dos remotos, de conseqüências profundas e decisivas (Guerreiro Ramos, 1948, p.1). O profissional da área poderia fornecer ao Estado um quadro realista das condições sociais segundo as quais as políticas públicas deveriam ser formuladas, tendo em vista a aceleração do processo de desenvolvimento dos denominados países periféricos.

\section{Ciências Sociais em uma era de mudanças}

No início dos anos 1950, o pensamento de Guerreiro Ramos esteve marcado pela definição de um projeto político para a Nação no qual assumia relevo o engajamento dos cientistas sociais nos processos de mudança vividos por aqueles países. Essas ideias foram expostas sistematicamente na 
forma de teses por ocasião do II Congresso Latino-Americano de Sociologia em 1953, gerando controvérsias no meio intelectual ${ }^{17}$. As teses foram publicadas posteriormente em Cartilha brasileira do aprendiz de sociólogo: prefácio a uma sociologia nacional, livro dedicado a Mário Magalhães ${ }^{18}$. A Cartilha foi uma espécie de síntese da sociologia de intervenção preconizada por Guerreiro Ramos. Na obra, é recorrente a referência à Comissão Econômica para a América Latina (Cepal), que, segundo o sociólogo, estaria afinada às suas propostas, tendo como principal objetivo tornar a política e o pensamento econômicos dos países latino-americanos fatores operativos do seu desenvolvimento (Guerreiro Ramos, 1954, p.61).

Note-se que as formulações de Guerreiro Ramos acerca do papel das Ciências Sociais assemelham-se ao alvo das críticas de outro sociólogo atuante na área da Saúde Pública nesse contexto, José Arthur Rios. Tendo realizado pós-graduação em Sociologia Rural nos Estados Unidos, Arthur Rios foi diretor da Seção de Pesquisa Social ligada à Divisão de Educação Sanitária do SESP nos anos 1950. Em artigo intitulado Ciências Sociais e Saúde Pública (1953), Rios se referiu à prática abusiva de determinados sociólogos, que extrapolariam o âmbito de suas atividades técnico-científicas para fazer política:

Parece-nos que o papel e a importância do sociólogo nos serviços públicos brasileiros não têm sido considerados devidamente. À tendência antiga para preterir essa contribuição está se substituindo hoje outra, não menos nociva, de exagerar a função do cientista social. Sob o nome de "acon-

17 Na polêmica acerca da cientificidade das Ciências Sociais e do seu caráter engajado envolveram-se sociólogos como Florestan Fernandes (Oliveira, 1995; Vianna, 1997) e Roger Bastide (Bariani Junior, 2008).

18 Note-se que Magalhães participou do congresso como relator da comissão presidida por Guerreiro Ramos, intitulada Estruturas nacionais e regionais (Anais do II Congresso Latino-Americano de Sociologia, 1957: 24). 
selhamento", tem-se ocultado uma insensata pretensão de certos sociólogos para monopolizar todo o planejamento e toda a política dos serviços em causa (Rios, 1953, p.2).

Para Arthur Rios, a atuação de cientistas sociais na área de Saúde Pública deveria se restringir a suas funções de consultor para técnicos e administradores, excluindo-se as tarefas de planejamento e controle (Idem) ${ }^{19}$. Nesse sentido, caberia àqueles profissionais a transmissão de perspectivas socioantropológicas que viabilizassem uma intervenção eficaz dos serviços de saúde e assistência junto às populações-alvo dos programas. Isto porque o contato entre os profissionais de saúde e sua clientela nas unidades sanitárias representava um encontro problemático de dois universos culturais distintos, do qual resultavam mal-entendidos. Os cientistas sociais, conhecendo as bases culturais das práticas e valores relativos à saúde daquelas populações de origem fundamentalmente rural, poderiam orientar a ação de educadores sanitários, provenientes de culturas urbanas, atuando como tradutores ou intérpretes entre os dois grupos (Maio; Lima, 2009).

Na base da concepção de Arthur Rios reside a ideia de que os hábitos de um indivíduo têm raízes na cultura do grupo (Rios, 1953a, p.3). No contexto rural brasileiro de economia pré-capitalista, o conceito moderno de saúde não continha qualquer valor social, ou ainda, nenhum sentido para o agricultor (idem, 1953, p.2). Deste modo, a verdadeira educação sanitária desses indivíduos só poderia ocorrer mediante intervenções nos

19 Este e outros dois textos de Arthur Rios na Revista do SESP foram republicados em artigo de Lima \& Maio (2010). Ainda que Guerreiro não seja nomeado no artigo de Rios, a referida tendência a "monopolizar" as políticas de saúde, a tomar para si as tarefas de planejamento, vai ao encontro da orientação científica exposta na Cartilha, segundo a qual o trabalho sociológico num país periférico [...] não pode[ria] permanecer descomprometido do processo de acumulação de capital, devendo ser convertido ao interesse nacional, isto é, às tarefas de promoção da autarquia econômica do país (Ramos, 1954, pp.68-69). Guerreiro é veemente e provocador neste ponto, afirmando que sociologia autêntica é aquela que participa do esforço político de construção nacional. Ver Ramos (1954) e Rios (1953; 1953a). 
grupos conformadores da comunidade local que desempenhavam a tarefa de controlar a permanência dos traços culturais que [interessavam] à sua duração (idem). Tratava-se da organização ou educação de comunidades, com a mobilização das principais lideranças e figuras locais, tendo em vista a valoração pelo grupo dos princípios, técnicas e hábitos da higiene moderna que se queriam inculcar (idem, p. 3).

Rios destacava que esses novos elementos poderiam ser mais facilmente introduzidos nas comunidades se passassem por um processo de adaptação às práticas locais ou de tradução cultural a partir do sistema de valores vigentes localmente. Em suas palavras, seria necessário que o traço cultural novo espos[asse] uma forma familiar aos seus beneficiários, pelo menos nas primeiras etapas da sua introdução (Rios, 1954, p. 175). A mudança, quando adotada inicialmente pelos líderes da região, encontraria menos resistência ao se difundir no grupo por meio de sua organização social. Com efeito, nesse período, o SESP buscou disseminar preceitos modernos de higiene por intermédio de curiosas (parteiras), e estudava ainda a possibilidade de se valer dos serviços de curandeiros (idem). É possível perceber, desse modo, que a viabilização dos serviços de saúde ocorreria a partir do interior do próprio universo cultural dessas localidades, de modo que a mudança de hábitos se processasse paulatinamente, sem transições bruscas e sem a desastrosa ruptura de velhas tradições que ameaçassem a comunidade enquanto todo integrado, provocando situações de choque e desestabilidade psicossocial de seus membros (Rios, 1954, p. 176).

O maior entrelaçamento entre os grupos locais e os serviços de saúde também deveria ocorrer mediante o estímulo, por parte do educador sanitário, à extensa participação das populações-alvo na tomada de consciência e na formulação de soluções para seus problemas. As intervenções governamentais não poderiam ser um processo estranho à população local que ela passivamente recebe das mãos generosas e paternais 
de administradores colocados a muitas léguas de distância (Rios, 1954, p.177). Teriam que ser resultado de cooperação, e não de coação (idem). Note-se que parte considerável do esforço em legitimar as técnicas de educação de grupos, cuja elaboração Arthur Rios atribuía a experiências anglo-americanas bem-sucedidas, concentrou-se na afirmação de sua virtude política enquanto meio adequado a um planejamento democrático, contraposto, por vezes, a um planejamento autoritário. Este seria implementado de cima para baixo, sob forma de ordem, lei ou decreto, não tendo a participação da população que, por consequência, não se interessaria pela marcha do plano, não fiscalizar[ia] sua execução, não se sent[iria] responsável pelos resultados, aguardando sempre, em morna apatia, que o governo faça, que o governo dê, que o governo assista (Rios, 1954, p.8)

$\mathrm{Na}$ Cartilha, a crítica de Guerreiro Ramos à transplantação de modelos estrangeiros - não apenas cognitivos, mas também técnicos e administrativos -, por especialistas brasileiros, esteve em parte dirigida ao tipo de intervenção social proposto por Arthur Rios no SESP20. Para Guerreiro, a orientação sociológica fragmentada, localista, tópica, na chave das mudanças sociais moleculares, representada pelo pensamento de Rios, pouco dialogava com a fase histórica de desenvolvimento em que se encontrava o país, a exigir uma perspectiva global a curto e médio prazo. Nas palavras de Guerreiro Ramos:

[...] para a melhoria das condições de vida do homem rural ou para a sua fixação, propõem os especialistas medidas diretas como organização de comunidades, educação sanitária, assistência social e outras em que transparecem vários equívocos. Um deles consiste em que se considera

20 A crítica de Guerreiro à "Sociologia enlatada" em contraposição à Sociologia autêntica, construída a partir do contexto social particular ao Brasil, é questão amplamente abordada. Ver, por exemplo, Oliveira (1995); Maio (1997); Villas Bôas (2006); Azevêdo (2006); Bariani Júnior (2008). Para uma análise do nacionalismo em Guerreiro Ramos, ver Abranches (2006). 
a sociedade rural como um sistema fechado, desarticulado da sociedade nacional - um evidente artifício. Além disto, essas medidas pretendem produzir efeitos impossíveis, efeitos - elevação dos gêneros e dos níveis de vida - que, classicamente, só podem ser obtidos mediante transformações tecnológicas da vida campestre, especialmente mediante o incremento da produtividade do trabalho rural. Em condições de baixa produtividade do trabalho rural, muito pouco resulta daquelas medidas (Guerreiro Ramos,1954, pp. 90-1, grifo nosso).

Note-se que, embora o nome de José Arthur Rios não seja citado na Cartilha, o sociólogo esteve entre aqueles que, na primeira metade dos anos 1950, conjugou explicitamente educação sanitária e organização de comunidades, relação explorada em seu livro $A$ Educação de grupos $(1954)^{21}$. A avaliação de Guerreiro Ramos acerca desse tipo de ação em saúde aproxima-se ainda de suas críticas à validade dos estudos de comunidade em voga no Brasil nos anos 1940 e 1950 e oriundos da prática de pesquisa nos Estados Unidos. Isto porque tais estudos sugeriam uma visão de comunidade fechada e desarticulada das macroestruturas socioeconômicas do país. Para Guerreiro, diante da tarefa de construção da nação, problemática particular da sociedade brasileira, as ciências sociais não poderiam distrair os parcos recursos disponíveis com pesquisas sobre minudencias da vida social (idem, 1954, p.16). A antropologia norteamericana, em particular, cometia o equívoco de considerar a mudança social em seus aspectos puramente superestruturais, [justificando-a] por intermédio de agências educadoras e sanitárias antes que mediante a alteração das bases econômicas e políticas da comunidade (Guerreiro Ramos, 1954, p. 126). O sociólogo asseverava que [n]ossos problemas culturais [seriam] particulares e dependentes da fase de desenvolvimento econômi-

21 Ver especialmente, neste caso, o capítulo XI, "O educador sanitário como organizador de comunidades" (Rios, 1954, pp. 286 - 297). 
co do Brasil. A mudança [...] de nossa estrutura econômica automaticamente soluciona[ria] tais problemas (idem).

Os cientistas sociais brasileiros, servindo-se criticamente ou apenas subsidiariamente daqueles modelos analíticos, deveriam investir em categorias sociológicas que expressassem mais adequadamente o processo histórico brasileiro, dentre as quais assumia centralidade a noção de industrialização. Em sua acepção sociológica, esta seria o processo civilizador responsável por verdadeiras mutações históricas (idem, p.93). Isto é, o crescente incremento técnico pelo qual passava o país não deveria ser estudado apenas à luz de suas implicações econômicas, mas também a partir de seus efeitos sobre os modos de vida e a estrutura de classes da sociedade, ou, nos termos do sociólogo, como influindo nos gêneros e níveis de vida das populações (idem). Com efeito, Guerreiro chegou a afirmar que a simples instalação de lâmpadas elétricas em moradias precárias [constituir-se-ia] num deflagrador de mudanças em massa, de atitudes humanas (Guerreiro Ramos, 1951, p. 27). Sob este prisma, os altos níveis de saúde e bem-estar social vigentes nos países industrializados [seriam] [...] efeitos e não causa da transformação tecnológica (Guerreiro Ramos, 1954, p.93).

A associação entre o setor Saúde e outros aspectos da vida das populações se fez presente nas reflexões de Arthur Rios e de Guerreiro Ramos. Apesar da ênfase na educação sanitária sociologicamente informada como forma de promover os modernos hábitos de higiene, Rios afirmava que o sucesso a longo prazo dos serviços sanitários dependia da transformação das técnicas de trabalho e da precária situação escolar no campo a fim de elevar os níveis de vida e a capacidade de produção (Rios, 1954, p.165). Note-se que as intervenções nessas diferentes frentes deveriam valer-se, todas elas, das técnicas de organização de grupo, ocorrendo de forma concomitante e articulada. Isto porque, mesmo a utilização de utensílios e ferramentas modernos, que do ponto de vista racional, urbano, ocidental 
representa[ria] um avanço para a comunidade, sendo culturalmente mediada, poderia sofrer a resistência de práticas tradicionais e crenças enraizadas (idem, p. 169). A ação pedagógica nas comunidades rurais também poderia contribuir para a melhoria das condições econômicas ao se voltar para o consumo, aumentando a capacidade de poupança, ensinando os consumidores a aumentar, pela indústria doméstica, a renda da família e a se organizar contra as pretensões descabidas do produtor ou do intermediário (idem, p.125). Rios também apontava os limites dessas intervenções locais quando afirmava que o incremento tecnológico da produção agrícola não implicaria necessariamente a mudança das relações sociais no campo, senão a mecanização da grande propriedade (idem). Nesse caso, a educação por si só pouco poderia conseguir se o técnico não conjugasse seus esforços num plano de reforma agrária que realiz[asse] uma distribuição mais justa da propriedade (idem, p. 125). Tem-se, assim, que Rios esteve atento ao risco de concepções isolacionistas de comunidade (idem, p. 80): em seu levantamento, o técnico não poderia perder de vista o fato de que ela faz parte de um todo, de um sistema, que abrange, não só a região, mas o Estado, o país, e às vezes mesmo transcende as fronteiras nacionais (idem, p.121). Para Guerreiro Ramos, não se tratava de adaptar as normas de saúde preconizadas pela higiene moderna ao universo cultural das comunidades rurais, na tentativa de vencer resistências, mas, antes, de promover a transformação em bloco do complexo rural, integrando-o à moderna economia nacional nascente. A educação sanitária por meio da organização de comunidades implicava em custos elevados para o estágio de desenvolvimento econômico do país, cujos recursos deveriam ser mobilizados para um amplo projeto de industrialização visando à sua transformação macroestrutural.

A relação estabelecida por Guerreiro Ramos entre os processos de desenvolvimento econômico-tecnológico e de mudança social, à primeira vista um tanto determinista, chega a sofrer uma tensão em certas oca- 
siões, cedendo a uma análise mais matizada, segundo a qual o aumento da produtividade e o avanço tecnológico seriam condições necessárias, embora não suficientes, para a alteração dos índices de saúde da população. Esta última perspectiva se entrevê mais nitidamente nas reflexões do sociólogo acerca dos hábitos e práticas culturais associados à medicina popular, compreendidos, em si mesmos, como fatores decisivos para o elevado índice de mortalidade infantil no país (Guerreiro Ramos, 1951a).

Valendo-se de imagens euclidianas, Guerreiro Ramos afirmou haver fortes antagonismos entre a mentalidade urbana dos profissionais de saúde e o universo cultural das populações rurais ${ }^{22}$. Os médicos, identificados aos conceitos modernos de saúde provenientes dos países desenvolvidos, buscavam em vão sensibilizar moralmente os grupamentos do interior brasileiro, e os de baixa renda em geral, para a gravidade de problemas de saúde como a mortalidade infantil. Para estes estratos sociais, a morte prematura de crianças detinha um sentido religioso específico - vontade ou favor de Deus; implicando ainda, na prática, a redução dos custos de subsistência das famílias (Guerreiro Ramos, 1951, p.33). Não figurava socialmente, pois, como um problema.

Note-se que, mesmo em seus aspectos mais específicos, as práticas de cura tradicionais, como as promessas, as romarias, as velas acesas a entidades místicas, o uso [...] de águas e ervas "santas", etc., para Guerreiro, deveriam ser interpretadas a partir de uma moldura universal, como cenário da pobreza (Guerreiro Ramos, 1951a, p.258). Afinal, tratava-se de hábitos típicos da pobreza, cuja influência negativa sobre a vitalidade

22 Sua reflexão sobre a intelectualidade brasileira esteve, a seu tempo, norteada pelo antagonismo entre "civilização de copistas" e "civilização autêntica", presente nas interpretações de Euclides da Cunha sobre o país. Para uma análise das continuidades e reelaborações da questão dos contrastes entre litoral e interior - delineada pelo autor de Os Sertões - nas Ciências Sociais, ver Lima (1998), especialmente o capítulo VI. 
humana se soma[ria] à do baixo poder aquisitivo (Guerreiro Ramos, 1951, p.26). Tais hábitos conformariam um verdadeiro complexo cultural, uma "cultura de folk". Noção bastante difundida neste período e elaborada pelo antropólogo norte-americano Robert Redfield, o termo designava grupos sociais pré-letrados, de origem rural, que, em contraposição aos núcleos urbanos, seriam dirigidos por hábitos e costumes legados pela tradição e partilhados por todos os seus membros, unidos por estreitos laços sociais (Pierson, 1962 [1945], p.141). Nas palavras de Guerreiro:

A pobreza em tôda a parte está no mesmo nível cultural. A sua concepção de saúde, da doença, da morte é a mesma, em toda parte. É uma concepção que se caracteriza por seu aspecto mágico e fatalista, concepção que [...] afirma a impotência da humanidade frente a fôrças misteriosas, de ordem natural ou social, que se acredita dirigirem a vida das sociedades e tornarem inevitável a perda de vidas humanas; concepção segundo a qual as doenças e os sofrimentos dos homens são o castigo merecido de seus êrros e pecados (Guerreiro Ramos, 1951a, p.258).

Na esteira das análises do sociólogo rural norte-americano T. Lynn Smith e do antropólogo Emílio Willems, Guerreiro reafirmava a coexistência de culturas tradicionais e modernas no país, a denominada heterogeneidade cultural $^{23}$. É nesse sentido que, ao crescimento econômico e ao desenvolvimento tecnológico, seria necessário acrescer a universalização da cultura no combate à mortalidade infantil (Guerreiro Ramos, 1951, p.39). O funcionamento ótimo dos serviços de saúde exigiria populações de elevado nível educacional, [...] suficientemente esclarecidas (idem). A julgar pela menção às baixas taxas de alfabetização infantil no Brasil, elaboradas

23 O antropólogo Emílio Willems trabalhou como professor da ELSP e da USP nas décadas de 1930 e 1940. Foi pioneiro na pesquisa de campo em Ciências Sociais, nutrindo a perspectiva de sua aplicabilidade nos programas de intervenção social do governo. Registro de sua participação na construção do campo antropológico no Brasil encontra-se em Corrêa (1987). 
pelo censo de 1940, Guerreiro Ramos se referia, neste caso, à incorporação dos estilos de vida modernos, por parte dos contingentes rurais, fundamentalmente por meio da promoção da educação básica (Guerreiro Ramos, 1951, p.22). Ao subsumir categoricamente a cultura tradicional e rural à pobreza e ao pauperismo, Guerreiro apresenta certa ambivalência na argumentação, considerando-se que os efeitos psicológicos de tal mudança não seriam automáticos. A mudança em massa dos hábitos de pobreza de uma população só a longo prazo se realiza[ria] (Guerreiro Ramos, 1951a, p.272273). Ou ainda, [d]epois de superada a condição econômica, só muito lentamente se supera, no caso, a condição cultural e psicológica, por si só, fator de alta mortalidade infantil (idem, p. 252-253, grifo nosso).

\section{Considerações Finais}

Os estudos de Alberto Guerreiro Ramos na área da saúde constituem momento importante na elaboração de uma sociologia engajada e de base autóctone. O início da carreira de sociólogo em agências governamentais de escopo nacional e sua experiência com puericultores, sanitaristas e técnicos da burocracia estatal foram elementos importantes para sua reflexão e posicionamento intelectual. Seus trabalhos sobre delinquência juvenil nos anos 1940, se, por um lado, registram o afã da sociologia de seu tempo por novos padrões de cientificidade, indicam também o papel interventor que o cientista social era instado a desempenhar, no exercício das "clínicas sociológicas" e na assistência às "crianças desajustadas". A convicção do sociólogo em uma ciência engajada e redentora foi reforçada diante das discussões acerca do fenômeno da mortalidade infantil, alçado à categoria de problema nacional, a exigir profundas mudanças sociais sob a ação racional e planejada do Estado, o que implicava o aval científico da Sociologia. 
Ressalte-se que seus estudos no campo da saúde pública permitem uma análise mais rica e matizada sobre o tema das relações estabelecidas entre a Sociologia e o pensamento sanitarista dos anos 1950. A afinidade intelectual entre Guerreiro Ramos e Mário Magalhães da Silveira, tendo início ao final dos anos 1940, adentrou a década seguinte. Ela se expressa fundamentalmente no enfoque comum sobre as condições socioeconômicas necessárias à melhoria do quadro de saúde das populações e na crítica ao uso de modelos de ação sanitária norte-americanos sem a devida consideração do contexto nacional. Além de ter participado do II Congresso Latino-Americano de Sociologia, como relator na comissão presidida por Guerreiro, Magalhães foi convidado a ministrar aulas, em meados dos anos 1950, nos cursos oferecidos pelo ISEB.

A análise do pensamento de Guerreiro Ramos neste período indica, desse modo, que a Saúde foi um tema-chave acionado tanto para a composição do retrato de uma nação subdesenvolvida, cindida entre a moderna mentalidade das elites urbanas e os hábitos sociais típicos de pobreza, quanto para a formulação de um projeto político capaz de modernizá-la. Com efeito, o esforço para refletir a respeito das complexas relações entre saúde e desenvolvimento foi uma constante entre cientistas sociais envolvidos em agências do Estado, como foi o caso de José Arthur Rios. Confrontando-se as concepções de Guerreiro Ramos e Arthur Rios, observa-se que ambos ressaltaram, ainda que conferindo pesos distintos, a importância da dimensão cultural nos processos de mudança social. Arthur Rios não ignorava a estrutura socioeconômica específica na qual transcorria a dinâmica cultural das populações, mencionando a economia pré-capitalista da zona rural e a acentuada distinção de classes existentes no país (1953a, p. 3). Para Rios, contudo, a organização de comunidade não seria técnica privilegiada [somente aplicável] a populações ricas e desenvolvidas, nem restritas a culturas particulares (Rios, 1954, p. 295). Do mesmo modo, a intervenção 
local, servindo-se das técnicas de educação de grupos como modo de mobilizar populações e reeducar mentalidades, deveria ser empregada para além do setor Saúde, articulando-se aos serviços de fomento à produção e vitalizando o ambiente da escola (idem, p. 296). Guerreiro Ramos, por seu turno, deu relevo ao fundamento econômico do "atraso", julgando inócua qualquer ação que não atentasse para os determinantes macroestruturais da saúde das classes baixas. Reiterava a importância do aumento da produtividade da força de trabalho nacional como a via de capitalização do país e de melhoria progressiva das condições de vida das massas, ainda que, em sua argumentação por vezes ambígua, os índices de saúde não decorressem imediatamente de tais mudanças. Ao que parece, tratava-se de estabelecer uma relação de prioridades para certos investimentos e políticas de desenvolvimento em razão daquilo que o sociólogo avaliava como os escassos recursos públicos do país.

\section{Referências}

ABRANCHES, A. M.. Nacionalismo e democracia no Pensamento de Guerreiro Ramos. Tese (Doutorado em Ciência Política) - Instituto Universitário de Pesquisas do Rio de Janeiro, Rio de Janeiro, 2006.

ABREU, A. A. (Coord.). Dicionário Histórico Biográfico Brasileiro pós 1930. 2ª ed. Rio de Janeiro: Ed. FGV, 2001. Disponível em: http://cpdoc.fgv.br/producao/ dossies/Jango/biografias/san_tiago_dantas. Acesso em: 17 maio 2011.

AZEVÊDO, Ariston. A sociologia antropocêntrica de Alberto Guerreiro Ramos. 2006. Tese (Doutorado em Sociologia Política) - Universidade Federal de Santa Catarina, Florianópolis.

ALMEIDA, M. H. T. Dilemas da Institucionalização das Ciências Sociais no Rio de Janeiro. In: MICELI, S. (Org.). História das Ciências Sociais no Brasil. São Paulo: Sumaré, v.1. p. 223 - 256. 2001.

BARIANI JUNIOR, E. Guerreiro Ramos e a redenção sociológica: capitalismo e sociologia no Brasil. 2008. 329f. Tese (Doutorado em Sociologia) - Programa de Pós-Graduação em Sociologia da Faculdade de Ciências e Letras da Universidade Estadual Paulista "Julio de Mesquita Filho", São Paulo. 
BIZZO, M.L.G.; LIMA, N. T. XIV Congresso Brasileiro de Sociologia, 14, 2009, Rio de Janeiro. O projeto civilizatório nacional do Instituto de Nutrição da Universidade do Brasil (1946 - 1960).. Rio de Janeiro, 2009. Disponível em: <http://starline.dnsalias.com:8080/sbs/ arquivos/15_6_2009_16_47_14.pdf>. Acesso em: 02 mar. 2010.

BOLETIM TRIMENSAL DO DEPARTAMENTO NACIONAL DA CRIANÇA. Rio de Janeiro: Imprensa Nacional, no-s. 1 - 24, 1940 - 1945.

BOTElHO, A.. Passado e futuro das interpretações do país. Tempo social. São Paulo, v. 22, n. 1, 2010. Disponível em: <http://www.scielo.br/scielo. php?script $=$ sci_arttext $\&$ pid $=S 010320702010000100003 \& \operatorname{lng}=$ pt $\& n r m=i s o>$. Acesso em: 03 ābr. 2011.

CAMPOS, A. L. V. Políticas Internacionais de Saúde na era Vargas: o Serviço Especial de Saúde Pública, 1942 - 1960. Rio de Janeiro: Ed. Fiocruz, 2006.

CEPÊDA, V. O pensamento político de Celso Furtado - Desenvolvimento e Democracia. In: BRESSER-PEREIRA L.C.; REGO, M. (Org.). A grande esperança de Celso Furtado. São Paulo: Editora 34, 2001.

CHAPOULIE, J. M. La tradition sociologique de Chicago (1892-1961). Paris: Éditions du Seuil, 2001.

CONGRESSO LATINO-AMERICANO DE SOCIOLOGIA, 2., 1957, Rio de Janeiro. Anais. Rio de Janeiro: Associação Latino-Americana de Sociologia (ALAS), 1957. Tomo I. p. 313.

CORRÊA, M. História da antropologia no Brasil: 1930-1960 - testemunhos. São Paulo: Vértice, Editora Revista dos Tribunais; (Campinas, SP); Editora da UEC, 1987. COULON, A. A Escola de Chicago. São Paulo: Papirus, 1995.

DEL VECCHIO, A.; DIÉGUEZ, C. (Org.). As pesquisas sobre o padrão de vida dos trabalhadores da cidade de São Paulo. São Paulo: Ed. Sociologia e Política, 2008.

ESCOREL, S. Saúde Pública: utopia de Brasil. Rio de Janeiro: Relume-Dumará, 2000.

FERREIRA, M. M.; MOREIRA, R.L. (Org.). CAPES 50 anos: depoimentos ao CPDOC/FGV. Rio de Janeiro: Fundação Getúlio Vargas, CPDOC; Brasília, DF, 2003. Disponível em: <http://cpdoc.fgv.br/producao_intelectual/arq/1319_Capes04.pdf. $>$ Acesso em: 02 mar. 2010.

FONSECA, C. M. O. Modelando a Cera Virgem: A saúde da criança na Política Social de Vargas. 1990. 176f. Dissertação (Mestrado em História) - Instituto de Ciências Humanas e Filosofia, Universidade Federal Fluminense, Rio de Janeiro. 
GUERREIRO RAMOS, A. Aspectos Sociológicos da Puericultura. Coleção D.N.C., no109, Imprensa Nacional, Rio de Janeiro, 1944.

GUERREIRO RAMOS, A. Uma Concepção Multidimensional do Comportamento. Jornal de Pediatria, Rio de Janeiro, p. 314 - 326, jul., 1944a.

GUERREIRO RAMOS, A. As Implicações Sociológicas da Puericultura. Separata de: Revista Pediatria e Puericultura, Salvador, ano XV, n.1, set., 1945.

GUERREIRO RAMOS, A. Pequena Bibliografia do Estudo do Padrão de Vida. Revista do Serviço Público, Rio de Janeiro, v.2, n.1/2, p. 136 - 139, mai./ jun. 1947.

GUERREIRO RAMOS, A. Aspectos Econômicos da Mortalidade Infantil. A Manhã, Rio de Janeiro, p.1/3, 4 abr.1948.

GUERREIRO RAMOS, A. Tratamento estrutural da mortalidade infantil. A Manhã, Rio de Janeiro, p. 2, 31 dez. 1950.

GUERREIRO RAMOS, A. O problema da mortalidade infantil no Brasil. Revista Sociologia, São Paulo, v.XIII, p. 1 - 43, mar. 1951.

GUERREIRO RAMOS, A. Pauperismo e medicina popular. Revista Sociologia, São Paulo, v.XIII, n.3, p.252 - 273, ago. 1951a.

GUERREIRO RAMOS, A. Cartilha brasileira do aprendiz de sociólogo: prefácio a uma sociologia nacional. Rio de Janeiro: Ed. Andes, 1954.

GUERREIRO RAMOS, A. Sociologia e Saúde Pública. O Jornal, Rio de Janeiro, p.2, 10 jul. 1955.

GUERREIRO RAMOS, A. Sociologia de la mortalidad infantil. México: Editora da Universidad Nacional, 1955a.

GUERREIRO RAMOS, A. Entrevista com Guerreiro Ramos. In: OLIVEIRA, L.L. A Sociologia do Guerreiro. Rio de Janeiro: Editora UFRJ, 1995. p. 131 - 183.

GUERREIRO RAMOS, A.; GARCIA, E. S. Notícia sobre as pesquisas e os estudos sociológicos no Brasil (1940 - 1949). Conselho de Imigração e Colonização, Rio de Janeiro, 1949.

HOCHMAN, G.. O Brasil não é só doença: o programa de saúde pública de Juscelino Kubitschek. História, ciência, saúde - Manguinhos, v.16, suplemento 1, julho de 2009, pp. 313-331.

LIMA, N. T.. Um sertão chamado Brasil: intelectuais e representação geográfica da identidade nacional. Tese de Doutorado. IUPERJ, Rio de Janeiro, 1998.

LIMA, N. T.; MAIO, M. C.. Tradutores, intérpretes ou promotores de mudança? Cientistas Sociais, educação sanitária rural e resistências culturais (1940-60). Sociedade e Estado, v. 24, n.2. 2009. 
LIMA, N. T.; MAIO, M. C. Ciências Sociais e educação sanitária: a perspectiva da Seção de Pesquisa Social do Serviço Especial de Saúde Pública na década de 1950. História, Ciências, Saúde - Manguinhos, v. 17, n.2. 2010.

LIMONGI, F. A Escola Livre de Sociologia e Política em São Paulo. In: MICELI, S. (Org.). História das Ciências Sociais no Brasil. São Paulo: Sumaré, 2001, v.1. p. $257-276$.

MAGALHÃES, M. Houve um colapso no plano nacional de saúde? - Aumento e barateamento dos gêneros alimentícios, providencia preliminar para resolver o problema de saúde publica. O Jornal, Rio de Janeiro, p.8, 24 ago. 1948.

MAGALHÃES, M. Conferência proferida pelo Ministro da Saúde (05/09/54 20/12/55) Aramis Athayde na Academia de Medicina Militar, no Rio de Janeiro em 27 de junho de 1955. In: SILVA, R. S.; DE MORELL, M. G. G. (Org.). Política Nacional de Saúde Pública - A trindade desvelada: economia - saúde - população. Rio de Janeiro: Revan, 2008. pp. 27 - 41.

MAIO, M. C. (1996). "A questão racial no pensamento de Guerreiro Ramos", in Maio, M.C., Santos, R. V. (Org). Raça, ciência e sociedade. Rio de Janeiro: Ed. FIOCRUZ.

MAIO, M. C. A História do Projeto UNESCO: Estudos Raciais e Ciências Sociais no Brasil. 1997. 304f. Tese (Doutorado em Ciências Humanas: Ciência Política) Instituto Universitário de Pesquisa do Rio de Janeiro, Rio de Janeiro.

MAIO, M. C.; LIMA, N. T.. Tradutores, intérpretes ou promotores de mudança? Cientistas Sociais, educação sanitária rural e resistências culturais (1940-60). Sociedade e Estado, v. 24, n.2. 2009.

MICELI, S. Condicionantes do Desenvolvimento das Ciências Sociais. In: MICELI, S (Org.). História das Ciências Sociais no Brasil. São Paulo: Sumaré, 2001, v. 1. pp. $91-133$.

OLIVEIRA, L. L. A Sociologia do Guerreiro. Rio de Janeiro, Editora UFRJ, 1995.

OLIVEIRA, L. L As Ciências Sociais no Rio de Janeiro. In: MICELI, S. (Org.). História das Ciências Sociais no Brasil. São Paulo: Sumaré, 1995a, v.2. p. 235 - 307.

PEIXOTO, F. A. Franceses e norte-americanos nas Ciências Sociais Brasileiras (1930-1960). In: MICELI, S (Org.). História das Ciências Sociais no Brasil. São Paulo: Sumaré, 2001, v.1. p. 477 - 531.

PEREIRA, A. R. As Políticas Sociais e Corporativismo no Brasil: O Departamento Nacional da Criança no Estado Novo. 1992. 328f. Dissertação (Mestrado em História) - Departamento de História, Universidade Federal Fluminense, Rio de Janeiro.

PIERSON, D. Teoria e Pesquisa em Sociologia. São Paulo: Edições Melhoramentos, 1962 [1945]. 
PIERSON, D. Curso de Sociologia - DASP. Arq. Edgard Leuenroth - Fundo Donald Pierson. 1942.

RAMOS, Arthur. Os grandes problemas da antropologia brasileira. Revista Sociologia, São Paulo, v.X, n.4, p.213 - 226, 1948.

RIOS, J. A. A saúde como valor social. Boletim do Sesp, n. 33, p. 2-3, abr. 1953.

RIOS, J. A. Ciências sociais e saúde pública. Boletim do Sesp, n. 38, p. 2-3, set. 1953a.

RIOS, J. A. Educação de grupos. Rio de Janeiro: SNES, 1954.

SANTOS, W. G. D. Paradigma e história: a ordem burguesa na imaginação social brasileira. In: Roteiro bibliográfico do pensamento político-social brasileiro (1870-1965). Belo Horizonte: Editora UFMG; Rio de Janeiro: Casa de Oswaldo Cruz, 2002. p.19-71.

SCHWARTZMAN, S. Contribuição de Guerreiro Ramos para a Sociologia Brasileira. Revista de Administração Pública. Rio de Janeiro, v.17, n. 2, p. 30-34, abr./jun. 1983.

VALLADARES, L. P. (Org.). A Escola de Chicago - Impacto de uma tradição no Brasil e na França. Rio de Janeiro: IUPERJ, 2005.

VIANNA, L. W. A Revolução passiva: iberismo e americanismo no Brasil. Rio de Janeiro: Revan, 1997.

VILLAS BÔAS, G. Mudança provocada: passado e futuro no pensamento sociológico brasileiro. Rio de Janeiro: Editora FGV, 2006.

Recebido em: 22/07/2011

Aceite final: 23/11/2011 